\title{
Letras en el espejo \\ El constitucionalismo realista de Ferreyra y el realismo constitucionalista de Berni
}

\author{
Adriana do Carmo Figueiredo
}

\section{Consideraciones iniciales}

"El artista, el escritor, tienen que estar en la calle y meter la calle en los libros y en los cuadros". Antonio Berni ${ }^{2}$

Partiendo del epígrafe del renombrado pintor, muralista, grabador y profesor argentino Antonio Berni (1905-1981), sobre la necesidad de que tanto el artista como el escritor deben absorber los clamores de la calle, "estar en la calle y meter la calle en los libros y en los cuadros", pienso, en conformidad con el Dr. Raúl Gustavo Ferreyra (2006) ${ }^{3}$, que así también deberá ser una reforma constitucional o un proyecto de discusión política sobre la Carta de Valores de una nación. Según

1 Doctoranda en Letras, Estudios Lingüísticos en el programa POSLIN, Facultad de Letras, Universidade Federal de Minas Gerais (UFMG). Abogada constitucionalista. Docente en el Centro Federal de Educação Tecnológica de Minas Gerais (CEFET-MG), autora de varios artículos científicos y capítulos de libros sobre feminismo, género y estudios del discurso argumentativo. Posee Maestría en Letras, Estudios Literarios, por la Universidade Federal de Minas Gerais (UFMG). Actualmente, también es aspirante al Doctorado en Derecho Constitucional en la Facultad de Derecho, Universidad de Buenos Aires (UBA). Direcciones electrónicas: dricafigueiredo@uol.com.br / acfigueiredo.prof@gmail.com. Link de acceso al curriculum lattes: http://lattes.cnpq.br/5033301374875823.

2 Frase de Antonio Berni, en: Escritos y papeles privados. El fragmento citado fue entresacado del sitio electrónico: <http://coleccion.educ.ar/coleccion/CD5/contenidos/ docentes/sugeridas/culturas.html> / Accedido el 10 de febrero de 2016 (Colección educ.ar).

3 Este estudio utiliza la edición de 2014 de la tesis doctoral de Raúl Gustavo Ferreyra y, a partir de este momento, empleará el marco 2014 en las citas. Cfr.: Ferreyra, Raúl Gustavo. Reforma constitucional y control de constitucionalidad. $1^{\text {a }}$ ed. Ciudad Autónoma de Buenos Aires: Ediar, 2014. 
el constitucionalista, "sólo el poder constituyente que emana del pueblo, estrictamente, de los ciudadanos que componen el pueblo, debe crear el Derecho Constitucional, sistema que a su vez organiza al Estado Democrático" (Ferreyra, 2014, p. 15).

Cierta vez, Berni afirmó que "La obra se realiza plenamente conviviendo con el drama del hombre en su totalidad politica, religiosa y social, y en el infortunio y sobresalto de cada dia", lo que nos permite a priori pensar sobre el proceso sociodiscursivo constitutivo en que se realiza el texto constitucional (como obra jurídico-política) y a posteriori sobre la efectividad de derechos y garantías que se plantean en el producto lingüístico constitucional que sintetiza (o debería sintetizar) todos los matices sociales, políticos, étnicos y culturales que revelan verdaderas representaciones del mundo y de la trayectoria de cada uno de los sujetos de derecho que componen la vida en sociedad.

El artista en mucho tiene en común con el jurista o con los sujetos que piensan el Derecho, en la medida en que todos se encuentran en búsqueda del inconsciente colectivo (o del imaginario social) de una determinada sociedad para la creación de imágenes plásticas o de comandos normativos que puedan reflejar los clamores sociales y políticos que estructuran los pilares y el cuerpo del sistema jurídico. En este sentido, ¿no sería la Constitución también una especie de figuración o mise en scène comprometida que refleja los dramas existenciales entre pueblo y Estado? Mejor diciendo, ¿no sería la Constitución la pintura lingüística de las propias demandas o de las contradicciones que se extraen de la genialidad creadora del poder soberano del pueblo? Propone Ferreyra el siguiente interrogante: “een

\footnotetext{
4 Pensamiento de Antonio Berni citado por: PEPE, Pablo F. Un hombre, un pintor, un maestro: Pablo F Pepe. - $1^{\text {a }}$ ed. - Don Torcuato: Autores de Argentina, 2009.

5 Término empleado en el Análisis del Discurso de Patrick Charaudeau para señalar la puesta en escena de los sujetos de la acción que componen el acto de lenguaje y el juego de estrategias comunicativas de que se valen esos sujetos en la producción de sentidos. Cfr.: Charaudeau, Patrick. Des conditions de la mise en scène du langage. In: Decrosse, Anne (dir.). L'esprit de société: vers une anthropologie social du sens. Paris: Mardaga, 1993. p. 27-65
} 
qué sentido la Constitución Federal de la Argentina es un instrumento, lato sensu, para garantizar y encauzar la democracia?" (Ferreyra, 2014, p. 36).

Es cierto que Berni, cuando regresó a la Argentina en 1931, encontró el país inmerso en una grave crisis social y económica. Había desocupación y ollas populares por todas partes. Así, humanista por naturaleza, Berni puso su pintura al servicio del ideal humano y social, y se conmovió con su propia historia o con la historia de su gente. Sin lugar a duda, su pintura pasó a revelar la expresión de una impactante figuración comprometida con el componente humano y la retratación de la sociedad de su tiempo por la mirada atenta del artista. A su vez, Ferreyra sostiene que sólo el poder constituyente del pueblo debe crear el Derecho Constitucional que organiza el Estado Democrático, ésta es la idea que compone el marco de referencia en su tesis doctoral. Declara el constitucionalista que le provoca inquietud la escandalosa laguna que ha separado la teoría de la práctica, en que se percibe "la letra constitucional con su vulneración o desborde, en rigor, del difícil itinerario de la democracia constitucional en la Argentina" (Ferreyra, 2014, p. 37). En este fragmento textual, así como en todo el cuerpo pensante de su obra doctoral, Ferreyra parece declarar en su narrativa jurídica, por medio de estrategias discursivas presentes en las entrelíneas de su texto, que la Constitución de la Nación no puede ser meramente una pieza de museo a la espera de que los visitantes o los inspirados por el arte la recluten o la vean en su esencia plástica y figurativa. Es mucho más que eso, la Constitución es la Ley Fundamental que posee fuerza normativa ya que preceptúa una rigurosa concepción de las garantías constitucionales que deben ser vistas y reclutadas por el ciudadano cotidianamente como herramientas capaces de hacer efectivas las pautas del sistema en su integridad, "en cualquier circunstancia de modo, tiempo y lugar, frente a cualquier voluntad o fuerza, por poderosa o enérgica que sea" (Ferreyra, 2014, p. 82). De este modo, la defensa de la Constitución debe ser una misión diaria y vigilante que consiste en protegerla contra los intentos de 
los transgresores con sus maniobras de quebrantamiento de las garantías constitucionales.

En sus cuadros monumentales, Berni expresa su repudio ante la injusticia social imperante en su tiempo y muestra tanto la miseria como el desamparo de las clases más marginadas de la sociedad argentina. Las obras Desocupados o Desocupación y Manifestación (1934) corresponden al contexto histórico de la Argentina de los años de 1930 y forman parte del cuerpo analítico de este estudio que tiene como objetivo trazar algunas observaciones sobre el realismo social de Berni que parece proponer sombras pictóricas del constitucionalismo argentino y discutir la perspectiva constitucional realista de Ferreyra respecto a la temática de la posible inconstitucionalidad de una reforma constitucional, tomando en cuenta su relación directa con las ideas de soberanía popular y democracia. Para la composición del marco teórico de esta investigación han sido empleadas las obras Le bon gouvernement de Pierre Rosanvallon, El susurro del lenguaje (Le Bruissement de la langue) de Roland Barthes, La Arqueología del Saber (L'Archéologie du Savoir) de Michel Foucault, además de aportes de otros importantes pensadores como Diego Valadés, Patrick Charaudeau, todos en diálogo con Raúl Gustavo Ferreyra en su magistral tesis doctoral Reforma Constitucional y Control de Constitucionalidad.

\section{Raúl Gustavo Ferreyra y Antonio Berni, metalenguaje en las telas jurídicas: aproximaciones entre arte, ciencia y política}

Raúl Gustavo Ferreyra (2014), en su obra Reforma Constitucional y Control de Constitucionalidad, empieza su saga ${ }^{6}$

\footnotetext{
6 El término "saga" está siendo empleado en este estudio en sentido figurativo para designar la hazaña heroica del jurista Ferreyra que, a la similitud de un caballero andante, emprende los trazos solitarios de su pluma en la tesitura de su narrativa jurídico-política en defensa de la Constitución contra los molinos (ni siempre de viento) de los transgresores de las garantías constitucionales. A éstos que llamo metafóricamente de molinos, Ferreyra viene llamando, en sus recientes publicaciones, de "poderes salvajes".
} 
intelectual como un itinerante y solitario pensador (algo quijotesco en sus luchas) ${ }^{7}$ proponiendo un diálogo, mejor diciendo, un contrato de lectura ${ }^{8}$, una especie de pacto comunicativo con su lector imaginario desde el prólogo 9 de su obra, como si fuera un novelista, un dramaturgo, desde luego, un artista asumiendo su lugar en el espacio movedizo de la enunciación, entendido aquí como centro de la creación artístico-teórica del pensamiento que pretende captar un fragmento del mundo ${ }^{10}$ reflejado en el propio fragmento del sistema constitucional, caracterizado como fenómeno cultural ${ }^{11}$. En este instante enunciativo, en que el lenguaje susurra en el ya-dicho más allá de la palabra y la escritura ${ }^{12}$, es establecido el acuerdo de lectura que el sujeto-enunciador Ferreyra construye con su interlocutor ficcional $^{13}$ al exponer su inquietud: la de una posible inconstitucionalidad de una reforma constitucional y el interrogante

\footnotetext{
7 Dejo en este estudio las huellas de la metáfora del Don Quijote y su representativa crítica social como señal de un futuro artículo científico que pretendo escribir sobre la tesis de Ferreyra y la obra de Cervantes, tomando en cuenta sus maniobras lingüísticas polifónicas que se centran en el personaje como foco narrativo para la construcción de la realidad bajo puntos de vista.
}

8 Sobre los contratos de Lectura, recomiendo la obra: Charaudeau, P. Langages et discours. Paris: Hachette, 1983.

9 Importante comentar que el prólogo, además de ser un texto preliminar, escrito por el autor o por otra persona para introducir la lectura, es también un discurso que, en el teatro griego y latino, y también en el moderno, precede al poema dramático.

10 Cfr.: Sobre el tema, Ferreyra recomienda la lectura de RUSSEL, Bertrand. Nuestro conocimiento del mundo externo. Buenos Aires: Losada, 1946, p. 44

11 Cfr.: Ferreyra explica, en conformidad con Diego Valadés, que el Derecho es un fenómeno cultural. La cultura jurídica es una de las claves para que el gobernante sea más recatado y el gobernado menos encogido. Sin cultura jurídica unos atropellan, aun sin quererlo, y otros son atropellados, incluso sin saberlo. Valadés, Diego. La lengua del Derecho y el derecho de la lengua, discurso de ingreso a la Academia Mexicana de la Lengua. 25 de agosto de 2005, Universidad Autónoma de México y Academia Mexicana de la Lengua. México, 2005, p. 28

12 Cfr.: Barthes, Roland. El susurro del lenguaje - Más allá de la palabra y la escritura. 1 ed. (Título original: Le Bruissement de la langue, traducción: C. Fernández Medrano). Ciudad Autónoma de Buenos Aires: Paidós, 2013.

13 Para la comprensión y definición de los sujetos del lenguaje, recomiendo la obra: Charaudeau, P. Langages et discours. Paris : Hachette, 1983. 
de que, en caso de producirse o aceptarse que ello pueda suceder, qué órgano o sujeto ha de ser llamado para resolverlo.

Afirma el jurista que la Constitución es instrumento de integración, unidad y dirección del sistema jurídico, a condición de que, por intermedio de sus garantías, razonablemente, se intente respaldar las propias pretensiones de vigencia de las reglas constitucionales. Luego, concluye, reforma de la Constitución y control de constitucionalidad son, probablemente, dos garantías, dos paradigmas del sistema constitucional. Tomando en cuenta este contexto, enseña Ferreyra (2014) que es habitual pensar que reforma y control judicial de constitucionalidad operen coordinadamente, propiciando la estabilidad y perdurabilidad de las disposiciones contenidas en la Ley Mayor. Sin embargo, no se puede olvidar que existe un conflicto entre reforma y control, y no la cooperación entre ellos.

El método utilizado por Raúl Gustavo Ferreyra para exponer sus ideas presenta similitud con las técnicas artísticas empleadas por Antonio Berni, en la medida en que ambos buscan captar el sentido de aquello que forma parte de sus propias realidades, ora como artista, ora como escritor-jurista, en búsqueda de las verdades (vicisitudes) que componen la esencia del ser en su tiempo y en el espacio rescatados por la alteridad. Así siendo, enseña Ferreyra (2014) que cuando la intención es obtener un resultado determinado, en una tesis doctoral, "cuya originalidad puede constituir un seguro aporte al grado de conocimiento que posee el saber jurídico, es indispensable que se dibuje el camino que conducirá al destino deseado. 'Método', en su etimología, revela la presencia del vocablo griego 'odos', cuyo significado es, precisamente, camino" (Ferreyra, 2014, p. 12-13).

De este modo, el constitucionalista parte del entendimiento de que el método en cuanto a un conjunto de operaciones, calculadas y ordenadas, dirigidas a un objetivo, es también una actividad a que se propone realizar bajo una vigilancia crítica para la construcción de un fin determinado. En sus palabras: 
Perseguir el ideal de racionalidad significa construir teorías, pero teniendo en cuenta que el conocimiento del mundo, del mundo que "elegimos", será siempre provisional e incierto, situación que de ninguna manera excluye la actividad científica: la exige por derecho propio, si es que se ha de estar contestes en la idea de progreso, entendido este término en sentido no neutral, como aumento de la verdad y de la consistencia de nuestros saberes (Ferreyra, 2014, p. 13).

Al enunciar que el conocimiento "del mundo que 'elegimos' será siempre provisional e incierto, situación que de ninguna manera excluye la actividad científica", Ferreyra propone una interesante definición del concepto de ciencia que me parece muy familiar con las ideas de Roland Barthes cuando éste sugiere una relación directa de la propia ciencia al conjunto de los saberes científicos sociales y humanos. Para Barthes, la ciencia es definida como un "estatuto" que tiene determinación social. De este modo, "cualquier materia que la sociedad considere digna de transmisión será objeto de una ciencia" (Barthes, 2013. p. 14).

En una línea semejante, Antonio Berni, cierta vez, dijo que todo artista y todo arte es, en definitiva, político, o podríamos decir que todo arte admite también una lectura política, y es precisamente ese modo de leer que torna viable pensar el arte también como producción del saber científico. Eso nos permite concluir como intérpretes de las obras de Berni que la lectura fenoménica de sus pinturas es fundamental, y que no se trata de algo obvio, pues también el arte es un campo de incertidumbres en lo que se refiere a la mirada particular del artista sobre el fragmento del mudo a que se propuso captar. También es el arte que permite el juego de sentidos a que se propone el intérprete con su propio conocimiento de mundo y el repertorio cultural de que dispone y del cual se apropia en la construcción subjetiva de sus propias lecturas sobre el objeto artístico. De este modo, comprender las obras de Berni va más allá de una lectura meramente estética, ya que adentramos en las sendas 
políticas reclutadas por el artista; así como comprender las teorías de Ferreyra va más allá de una lectura estrictamente jurídica, pues ambos, artista y constitucionalista, dejan sus propias huellas de los recortes del mundo que rescataron en sus miradas transpuestas en lienzos o en escrituras.

Según Roland Barthes (2013), la literatura posee los mismos contenidos que la ciencia, es decir, no existe una sola materia científica que, en dado momento, no haya sido revelada por la literatura universal. Luego, "el mundo de la obra literaria es un mundo total en el que todo el saber (social, psicológico, histórico) ocupa un lugar, de manera que la literatura presenta ante nuestros ojos la misma gran unidad cosmogónica de que gozaron los griegos antiguos, y que nos está negando el estado parcelario de las ciencias de hoy" (Barthes, 2013, p. 14). Como la Literatura, entiendo que de la misma forma se ubica el Arte universal, pues las dos formas plurales de expresión son manifestaciones de las miradas del hombre que presentan sus programas de investigación, sus maneras de captar ecos de la realidad que oscilan de acuerdo con las escuelas y las épocas, así como sucede con los cambios de la ciencia. El hacer artístico-literario también posee sus reglas de investigación, y, a veces, incluso, pretensiones experimentales.

En su trayectoria creativa e intelectual, Berni se puso a servicio de las preocupaciones y desvelos del hombre de su tiempo. Según los estudiosos ${ }^{14}$ de las obras de Berni, en 1932, el artista introdujo el surrealismo en las artes visuales argentinas, revelando las urgentes necesidades sociales y políticas de su país y del mundo, lo que llevó el pintor a construir un moderno realismo crítico, con destacada perspectiva militante. Berni se preocupó por reconducir sus contenidos, por medio de experimentos que mantuvieron contemporánea su forma de expresión. También se nota que Berni estuvo atento a las necesidades de cambio que emergían en el siglo XX, pues modernizó

\footnotetext{
14 Ideas entresacadas del sitio electrónico: <http://cvaa.com.ar/02dossiers/berni/3_intro_02.php>, accedido el 31 de enero de 2016.
} 
su pintura, investigó las posibilidades del mural, desarrolló el arte del objeto y el collage, y, además de eso, transformó el grabado, extrayendo de la sociedad de su tiempo las imágenes que compusieron su singular trazo impactante.

Recordemos que Ferreyra, a su vez, en un ejercicio de metalenguaje del yo-escritor con su propia producción escrita, también una modalidad de arte, afirmó que si hubiese que simplificar en muy pocas palabras el objeto de su contribución, podría formularse como el entendimiento teórico de un fragmento del mundo, de un fragmento del sistema constitucional, conforme dicho, captando éste como fenómeno cultural. Así siendo, alerta en su escritura que la comprensión más acabada o inacabada del referido fenómeno que se extrae de la cultura, transpuesto para el sistema constitucional que se analiza, permite distinguir, con seguridad, el grado de desarrollo cultural alcanzado por un pueblo; y por eso, declara con maestría que

es imposible suponer que los métodos bruscos o apresurados encuentren terreno propicio aquí para alcanzar la meta perseguida. Soy francamente partidario de los hechos nuevos y desconfio, por completo, del dogmatismo que se considere inexpugnable a los argumentos y a la experiencia (Ferreyra, 2014, p.14, subrayados míos).

Con esas palabras, Ferreyra inaugura un camino investigativo nuevo que permite pensar el derecho en diálogo permanente con aquello que emana del pueblo en su sentido más profundo, me refiero, a lo que sale efectivamente de las calles, de los clamores populares y de los dramas existenciales que componen el sery el tiempo del sujeto en el mundo con toda su diversidad de pensamiento o de creencia, y que, sin duda, es algo rescatado, de manera muy atenta, sensible y crítica, por la mirada contemplativo-política del artista o por la racionalidad estético-ética del jurista. Enfatiza el constitucionalista, desde el prólogo de su obra, a respecto de la existencia de una proposición que conduce toda, "absolutamente toda", su construcción conceptual: la de que el pueblo es el protagonista del Derecho Constitucional y que sólo el poder constituyente que emana de 
los ciudadanos que componen el pueblo debe crear el sistema que organiza al Estado Democrático de Derecho.

También me parece que Ferreyra al enunciar su desconfianza del "dogmatismo inexpugnable", señalada por el énfasis en la primera persona del verbo desconfiar ("desconfío"), estrategia lingüística de captación de su interlocutor para la significación de su discurso que expresa su declarada simpatía por los "hechos nuevos", plantea un entendimiento muy cercano a lo que Foucault propuso, en su obra La Arqueología del Saber (L'Archéologie du Savoir), respecto al empleo de conceptos de discontinuidad, ruptura y transformación, como movimiento de liberación de las nociones de continuidad y tradición. Foucault advierte que es necesario cuestionar ciertas síntesis acabadas y fabricadas que, a menudo, son aceptadas sin cualquier examen. "Es preciso desalojar esas formas y esas fuerzas oscuras por las que se tiene costumbre de ligar entre sí los discursos de los hombres; hay que arrojarlas de la sombra en la que reinan.” (Foucault, 2002, p. 35). Es también propuesta de Foucault que nos inquietemos frente a esos agrupamientos de conceptos a los cuales ya nos hemos acostumbrado. De este modo, tanto Foucault como Ferreyra nos invitan a analizar la complejidad del orden de los discursos que se han formado a lo largo de nuestra historia constitucional y a desconfiar del dogmatismo que se impone de manera absoluta con la finalidad de perpetuar las "continuidades irreflexivas".

Mas adelante, el sujeto enunciador creado por Ferreyra parece convencerse y querer también persuadir a su lector sobre el convencimiento de un camino inevitable: la supuesta admisión de que la Constitución canaliza jurídicamente el comando normativo democrático, pero, también, paralelamente sirve para comprobar la tensión entre referida regla democrática y la normatividad de la supremacía constitucional. Así, admite el constitucionalista que existen consecuencias inevitables y decisivas cuando se parte de la idea de que la juridicidad constitucional es una premisa que gana matices con la efectiva participación de los ciudadanos, en la condición de que ellos 
son los legítimos integrantes del pueblo soberano, pero se realiza por medio de los servidores públicos que ejercen funciones en las agencias políticas estatales. Ferreyra pone énfasis en la constatación de que referida premisa presenta más jerarquía que cualquier otra dentro del sistema.

Contemplado de esta forma, se afirma que, en sentido amplísimo existen dos jerarquías de decisiones políticas a las que cabe asignar, razonablemente, distinta legitimación: (a) decisiones del pueblo, (b) decisiones del gobierno. Las decisiones mencionadas en primer término configuran (crean) las reglas básicas del sistema; las mencionadas en segundo lugar son las que las interpretan y aplican (Ferreyra, 2014, p. 16).

Así como Berni, cada uno a su tiempo y a su manera, Ferreyra parte de la dimensión de la crisis institucional que atraviesa la Argentina para el abordaje del problema capital que se oculta en el posible conflicto que suscite una reforma de la Constitución federal argentina. Berni, a su vez, demuestra con su lenguaje pictórico que el arte no es algo ajeno a toda la experiencia propia de la vida del hombre, por eso parte de la crisis que atraviesa la sociedad de su tiempo y comprueba que ser artista no equivale, como muchos creen, a estar encasillado en una especulación abstracta específica, al revés, propone un abordaje en sus obras que atraviesa el mundo existencial que lo rodea y que llena de sentido político su hacer artístico.

En su obra Reforma Constitucional y Control de Constitucionalidad, Ferreyra propone algunos temas fundamentales que forman la tónica de este debate: (a) la forma de organización jurídica del Estado y su posible cambio, recomienda que se pase del federalismo al regionalismo o a diferente forma de descentralización política envolviendo territorio y poder; (b) la ruptura o el ablandamiento del sistema de gobierno presidencialista, sugiere una propuesta semipresidencialista o parlamentarista; (c) la determinación de la potestad de la Corte Suprema de Justicia de la Nación para que pueda intervenir en los conflictos entre los poderes del Estado; (d) la reorganización de los 
mecanismos de reclutamiento de los magistrados judiciales; y (e) la ampliación del contendido semántico del término "causa constitucional", para que se permita la acción declarativa de inconstitucionalidad (Ferreyra, 2014, p. 16-17).

$\mathrm{Al}$ observar con detalle y profundidad la materia, Ferreyra declara que "no puede existir serio debate racional si, previamente, no se analiza lo que otros piensan o han pensado sobre el mismo problema, o sobre aspectos del mismo" (Ferreyra, 2014, p. 17). Por eso, el constitucionalista analiza, por ejemplo, qué han hecho los operadores jurídicos para examinar una reforma constitucional y sus posibles vicios en el Derecho argentino; también son analizados el material originado por la dogmática constitucional, la jurisprudencia del más Alto Tribunal de Justicia de la Nación, además del análisis sobre la opinión de los jueces de la Supreme Court norteamericana cuando se ocuparon de la validez o invalidez de algunas reformas, todo eso forma parte del repertorio detallado del jurista que investiga la problemática de la posibilidad o imposibilidad de aceptar la inconstitucionalidad de una reforma (cuestión primaria) y propone el interrogante sobre qué órgano o sujeto es competente para ejercer el control de la enmienda (cuestión secundaria).

En la declaración de la originalidad de sus ideas, Ferreyra sostiene la posible inconstitucionalidad de una reforma y la caracteriza como el mayor conflicto que puede observarse dentro de un sistema jurídico estatal. Argumenta que referida inconstitucionalidad puede ser revestida de dos formas: una débil y otra fuerte. Se entiende que es débil cuando no se cumple con las pautas que reglamentan el propio proceso de reforma. Se dice que es fuerte e inválida cuando un cambio constitucional afecte una materia considerada intangible por la Constitución, de imposible cambio por violar una limitación material. Concluye que la invalidez de naturaleza material puede ser reconocida, sin embargo, no habrá posibilidades de corrección funcional. Así, a lo largo de su tesis, el constitucionalista trata de exponer las consecuencias que la inconstitucionalidad de una reforma acarrea. 
La Constitución argentina de 1853 / 1860 es vista como "espejo del patrimonio cultural" y también como reflejo de la hegemonía y de las esperanzas de una determinada clase de la Argentina. Enseña Ferreyra que referido texto constitucional con las reformas de 1866, 1898 y 1994 no contiene "explícitamente la asignación de competencia a un órgano o sujeto para resolver el control de inconstitucionalidad de una reforma constitucional" (Ferreyra, 2014, p. 20).

Por lo tanto, no existe una previsión en la Constitución argentina para decidir e interpretar la temática atinente a "los conflictos que se susciten respecto de las competencias y obligaciones entre los poderes estatales. Esta imprevisión del poder constituyente impide, razonablemente, asignar, propiamente, el control del proceso de reforma a un poder del Estado" (Ferreyra, 2014, p. 20). La propuesta de Ferreyra está pautada en un sistema mixto, en que la Corte Suprema de Justicia de la Nación tendrá la tarea de dirigir una previa declaración judicial (resolución) sobre el tema en cuestión al Congreso. Así, el órgano congresual, a su vez, deberá convocar el control ciudadano y la consecuente consulta popular. De este modo, concluye: "La juridicidad constitucional se basa en la premisa de que la voluntad de los ciudadanos que integran el pueblo posee mayor autoridad que la de quienes actúen en su nombre y representación" (Ferreyra, 2014, p. 21). Con esas palabras, Ferreyra nos enseña que es necesario que el pueblo sea visto efectivamente como el protagonista del Derecho Constitucional, volviéndose fundamental comprender sus demandas y sus reales deseos, ya que es "el pueblo el que decide la producción del sistema jurídico, y no al revés” (Ferreyra, 2014, p. 21). Delante de esa proposición capital del constitucionalista, propongo la reflexión de que el arte, expresión política del clamor popular y también mecanismo de producción científica, es un medio fundamental de aproximación y comprensión entre pueblo, ciencia y derecho. 


\subsection{El realismo social-artístico de Antonio Berni y sus raíces artístico-constitucionales}

Diego Valadés (2005) explica la relación entre el derecho y el lenguaje artístico-literario, poniendo en relieve el hecho de que es la literatura el puente más profundo que se produce entre el derecho y las artes. Sin embargo, es interesante mencionar que Valadés reconoce también la existencia de vínculos entre otras modalidades de arte como la música, el cinema y las artes plásticas de modo general, aunque destaca que la literatura por contener una característica propia de lenguaje por medio del manejo de palabras es la que mejor establece su relación con el derecho. Así define Valadés:

En el amplio campo de la creación literaria son muy frecuentes las preocupaciones asociadas a la justicia, a la equidad, a la libertad, al ejercicio del poder; en ocasiones incluso a las funciones judiciales y legislativas. Todas ellas, de manera implícita o explícita, están relacionadas con el derecho. Aunque es un territorio crecientemente explorado, los vínculos entre literatura y derecho constituyen una fuente inagotable para la reflexión que de manera progresiva convoca a un mayor número de estudiosos (Valadés, 2005, p.23).

Sin duda, Valadés tiene razón en observar la importancia de la literatura en ese diálogo lingüístico con el derecho que, en mucho, puede contribuir para la comprensión de la ciencia jurídica. Sin embargo, en mi opinión, no es simplemente la literatura o mayoritariamente el hacer literario que goza de ese prestigioso espacio dialéctico con el derecho. Pienso que la pintura y las artes plásticas de modo general también cumplen ese papel, ya que son modalidades de expresiones artísticas que poseen un leguaje propio rico de símbolos y sentidos. Por ser en gran medida simbólica por su naturaleza de arte visual, la pintura no posee un lenguaje fácil y muchas veces se vuelve objeto confinado a los museos que ni siempre es apreciado 
por un gran número de personas ${ }^{15}$. Muchas veces, la pintura adquiere una característica aristocrática ya que sólo las personas que han adquirido una cierta sensibilidad en la mirada o que se han introducido en su apreciación, por algún motivo, consiguen descifrar apropiadamente su lenguaje. El arte pictórico también es una modalidad de ficción en que el artista puede crear artificios para acentuar el carácter realista de sus obras por medio del empleo de líneas, colores, luces, perspectivas, volúmenes y otros aspectos que componen la sensación de solidez o de realismo que nosotros intérpretes del arte percibimos en los personajes o en los objetos representados.

Valadés (2005) distingue algunas vertientes en el proceso de investigación que envuelve el derecho y la literatura. La primera tiene que ver con el examen de las percepciones que los poetas, novelistas y dramaturgos han tenido respecto a los personajes y los episodios jurídicos, esa propuesta parece haber tomado otros rumbos a partir de las últimas cuatro décadas del siglo XX, momento que marca la centralización del enfoque investigativo por medio de la aplicación de la teoría literaria al análisis de los textos legales y jurisprudenciales. También destaca Valadés que, en la actualidad, existen dos nuevas ramas de análisis sobre los vínculos entre la palabra y la norma: uno que se refiere a la relevancia de los repertorios jurídicos (la lengua del derecho en sí) y otra que se refiere a la defensa jurídica de las lenguas (el derecho de la lengua).

Partiendo de mi hipótesis de que tanto las obras literarias como las artes plásticas en general pueden contribuir para las investigaciones jurídicas, ya que reflejan bajo metáforas, símbolos, colores, perspectivas y sombras un lenguaje plasmado

\footnotetext{
15 Situación que ocurre, especialmente, en Brasil, donde ni siempre las personas poseen hábitos de frecuentar a los museos del país para apreciar el arte pictórico. En este sentido, es importante comentar que, desde 2014, el Instituto Brasileiro de Museus (Ibram) y la Fundação Nacional das Artes (Funarte) vienen fomentando acciones que tienen la finalidad de proporcionar al público en general el acceso a espectáculos y otras actividades de excelencia artística a precios populares, estimulando, a medio plazo, mayor participación del público en los eventos artísticos.
} 
de valores relativos a la justicia, propongo como objeto de estudio las obras pictóricas de Antonio Berni, especialmente, Manifestación y Desocupados o Desocupación, ambas de 1934. Referidas creaciones artísticas reflejan el entorno social, político y jurídico de una época específica de la Argentina, captada por la mirada privilegiada de Berni que denuncia la exclusión, la pobreza, el hambre, la miseria, el desempleo y también los intentos de participación democrática, en que el pueblo con sus singularidades y rasgos idiosincrásicos se vuelve protagonista de la escena rescatada por el artista. En sus obras, Berni parece denunciar la opresión, el abuso del poder que deja al margen de la sociedad un gran número de personas y las injusticias provocadas por un sistema de gobierno ${ }^{16}$ que no pone en relieve las demandas del pueblo; además de eso, Berni parece anunciar la inconformidad del pueblo (en cierta medida resignada por lo que se nota en las expresiones retratadas), la ausencia del manejo real del poder soberano que debe emanar de los ciudadanos, la protesta como medio de reivindicación de derechos y sus acciones por la conquista de las garantías constitucionales, todo eso conjugado a su juego de colores, trazos superlativos, sombras y perfiles de los personajes que componen sus obras, a mi ver, ciudadanos con diferentes matices que se singularizan en sus luchas en medio a la colectividad.

\footnotetext{
16 En este sentido, es importante comentar que Pierre Rosanvallon advierte que las palabras "régimen" y "gobierno" se han confundido históricamente. Enseña que así ocurría en los siglos XVIII y XIX, cuando el vocablo "gobierno" era tomado como sinónimo de régimen y la idea correspondiente, como resultado, envolvía tanto el Legislativo como el Ejecutivo. Cf.: Rosanvallon, Pierre. Le bon gouvernement. Paris : Éditions du Seuil, 2015. También lo advierte Ferreyra, cuando alerta sobre las diferencias entre los términos "gobierno" con sus respectivas ramas y el término "Poder Ejecutivo" con la perspectiva constitucional. FERREYRA, Raúl Gustavo. Clases sobre Reforma Constitucional. Modalidad intensiva de cursos para el Doctorado. Departamento de Postgrado. Facultad de Derecho. Universidad de Buenos Aires (UBA), enero de 2016 (Notas de clase).
} 


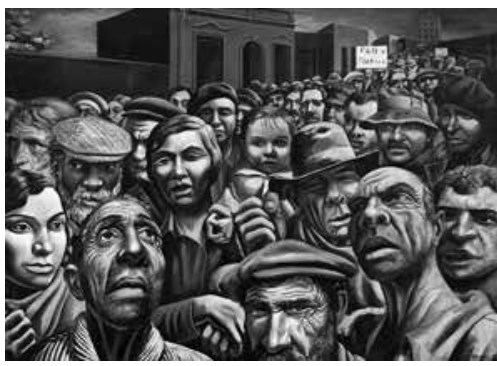

Antonio Berni. Manifestación, 1934, temple s/arpillera, $180 \times 249,5 \mathrm{~cm}$. Museo de Arte Latinoamericano. Buenos Aires. Algunos personajes se basan en fotos que Berni obtenía por sí mismo, del diario Crítica o de otras fuentes.

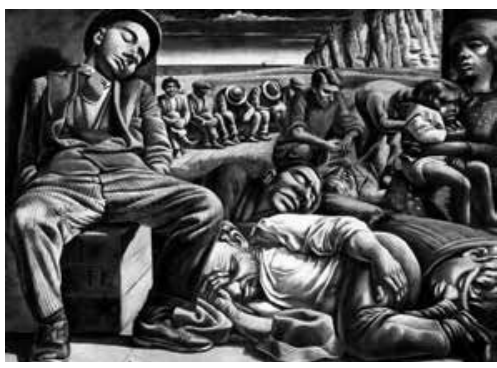

Antonio Berni. Desocupados o Desocupación, 1934, témpera s/arpillera, 218 x $300 \mathrm{~cm}$. Col. privada. Algunos personajes se basan en fotos que Berni obtenía por sí mismo o de otras fuentes.

Fuente: <http://cvaa.com.ar/02dossiers/berni/6_obras_1934_1.php> / accedido el 11 de febrero de 2016.

Antonio Berni es considerado uno de los artistas argentinos más importantes del siglo XX, y demostró, a lo largo de su historia, características de un sujeto comprometido, político y controversial que estuvo siempre atento a las tendencias contemporáneas, experimentando diferentes técnicas y materiales que respondían a corrientes artísticas diversas, pero sin perder el rasgo principal de su arte enraizado en la realidad social y política de su entorno. Cierta vez, dijo:

Todo artista y todo arte es, en definitiva, político, o podríamos decir -utilizando la terminología de modaque todo arte admite "también" una lectura política. En mi caso opino que una lectura política en mi obra es fundamental, que uno no puede obviarla y que, de hacerlo, la obra no será comprendida en profundidad: es más, creo que una lectura meramente estética sería una traición (Antonio Berni, 1905-1981) ${ }^{17}$.

\footnotetext{
17 Pensamiento de Antonio Berni. El fragmento citado fue entresacado del sitio electrónico: <http://www.literato.es/autor/antonio_berni > / Accedido el 10 de febrero de 2016.
} 
Las obras Manifestación y Desocupados o Desocupación, sin dudas, revelan la urgencia de denunciar la realidad social que estaban atravesando la Argentina y el mundo, en la década de 1930. Período histórico que trajo el registro del primer golpe militar sufrido por los argentinos. Sobre ese momento, Berni dijo: "El artista está obligado a vivir con los ojos abiertos y en ese momento (década del 30) la dictadura, la desocupación, la miseria, las huelgas, las luchas obreras, el hambre, las ollas populares, crean una tremenda realidad que rompían los ojos"18.

El eje central de las obras en comento muestra los conflictos de ese contexto, en que se destacan los problemas del desempleo, de la pobreza, del nazismo, del fascismo y de la guerra civil española, que parecen ser temas frecuentes en las obras de Berni, según mis investigaciones. En medio a ese escenario de opresión, Berni hizo del arte un medio de retratar lo humano, aspecto sobresaliente utilizado por este artista, en que se nota su compromiso social en rescatar las manifestaciones populares en diferentes matices.

En lo que se refiere a su obra Manifestación, son percibidos, en detalles, los rasgos sobresalientes y superlativos en la retratación de los rostros de los diferentes individuos, sujetos de derecho, que se superponen con una perspectiva de yuxtaposición de los personajes. En la escena pictórica, es inevitable el impacto que el artista provoca por medio de la multiplicidad de expresiones de cada uno de esos sujetos, cada cual con su particularidad expresiva, que forma en su dimensión dramática una mise en scène ${ }^{19}$ de representación performática-performativa

\footnotetext{
18 Informaciones extraídas de <http://www.elintransigente.com/argentina> /accedido el 11 de febrero de 2016.

19 Recordando que el término mise en scène es empleado en el Análisis del Discurso para señalar la puesta en performance de los sujetos que componen la escena discursiva con las estrategias comunicativas de que se valen en la producción de sentidos. En este caso, el discurso está siendo leído en este estudio por medio del arte pictórico y sus elementos de retratación bajo la mirada del enunciador-artista. Cfr. : Charaudeau, Patrick. Des conditions de la mise en scène du langage. In: Decrosse, Anne (dir.). L'esprit de société: vers une anthropologie social du sens. Paris: Mardaga, 1993. p. 27-65
} 
con enunciados propios del arte pictórico que revelan las arenas políticas y las luchas de clase. A mi ver, la obra Manifestación presenta trazos que comparten con la naturaleza de la performance, en sentido amplio, en que se nota el juego teatral del signo para la composición del ámbito político-social, de donde se extrae la exposición radical de los sujetos protagonistas del discurso (enunciadores-anónimos o personas del pueblo) así como del local de la enunciación marcado por el paisaje urbano. De este modo, cada rostro retratado por Berni aparece como si fueran distintos manifestantes con sus libertades individuales que componen el todo colectivo, representaciones de las múltiples identidades como movimiento de recuperación de comportamientos renunciados o recalcados ${ }^{20}$. En referida obra berniana, se reclama por "Pan y trabajo", signos lingüísticos que comprueban los clamores sociales de una colectividad compuesta por la diversidad y particularidad de cada individuo que con su voz silenciada proclama por la búsqueda de la efectividad de derechos y la instauración del sistema de garantías.

En la obra Desocupados o Desocupación, también se puede percibir una fuerte crítica social en favor de los menos favorecidos. La composición escénica de referida pintura muestra un enigmático aislamiento de los personajes dormidos que parecen revelar los dramas existenciales que resultan de la ausencia del trabajo, lo que implica el sentimiento de marginación o la condición de los que están fuera de la vida social-laboral y a la deriva del tiempo. El paisaje portuario trae una dimensión onírica para la pintura, matiz surrealista que recorrió buena parte de las obras de Berni, y que parece revelar la alucinación cotidiana de figuras fantasmagóricas superlativas que protagonizan la resultante del quebrantamiento de valores constitucionales como la dignidad de la persona humana. Desde la perspectiva discursiva que compone el juego performático

20 Cfr.: Ravetti, Graciela; Arbex, Márcia (org.). Performance, exílio, fronteiras: errâncias territoriais e textuais. Belo Horizonte: Departamento de Letras Românicas, Faculdade de Letras / UFMG: Poslit, 2002. 
de los personajes en destaque, se nota significativa presencia de personas de variadas identidades: anciano, joven, niño, mujer, todos ellos en postura de inercia que caracteriza el marasmo delante del desempleo, la falta de esperanza frente a la ausencia de oportunidades de trabajo y el consecuente vacío ocioso que se estampa en la fisonomía de las personas retratadas. Dijo Berni: "El artista está obligado a vivir con los ojos abiertos y en ese momento la dictadura, la desocupación, la miseria, las buelgas, las luchas obreras, el hambre, las ollas populares crean una tremenda realidad que rompian los ojos"21. De este modo, se puede percibir que el surrealismo y también el realismo crítico de Berni son combativos y revolucionarios, eso comprueba que el arte en la perspectiva berniana no es algo ajeno a la experiencia particular de la vida del hombre.

Importante comentar, según mis investigaciones, que, en 1934, se llevó a cabo una activa labor legislativa en la Argentina. Se sancionó la ley que tuvo como propuesta disponer un censo industrial, se crearon la Junta Reguladora de Vinos y la Junta Nacional como medidas para combatir la desocupación. También, se creó la Dirección Nacional de Parques Nacionales, que tenía como finalidad proteger a las obreras que eran madres. Hubo la creación de la ley que dispuso sobre las vacaciones anuales y las indemnizaciones por despido o fallecimiento de los trabajadores, la que unificó los impuestos internos, que hasta entonces eran recaudados por las provincias y que desde ese momento pasarían a ser tomados por la Nación ${ }^{22}$. De este modo, las grandes témperas sobre arpillera que Antonio Berni realizó en este período (Manifestación, 1934; Desocupados o Desocupación, 1934) forman el resultado del debate entre algunos artistas del momento, como los muralistas Diego Rivera en México y Candido Portinari en Brasil, por ejemplo, a respecto

\footnotetext{
21 Frase entresacada del sitio electrónico: <http://www.literato.es/autor/antonio_berni/> / accedido el 12 de febrero de 2016.

22 Informaciones extraídas del sitio electrónico: http://www.todo-argentina.net/historia/ decadainf/justo/1934.html / Accedido el 10 de febrero de 2016.
} 
del rol que debían ocupar el arte y también el artista en la sociedad. Berni dibujó con su trazo superlativo y su simbólico lenguaje pictórico-metafórico la narrativa de la historia de sus personajes, en protagonismo histórico, pero como resultante de los desechos de la sociedad y de la política que los excluyó durante largos años de su existencia. En esa posición de que el artista debe registrar el realismo de su tiempo, Berni como enunciador de sus obras parece darnos su testimonio de los márgenes de la sociedad industrial en que vivió componiendo los residuos de acontecimientos, huellas de historias individuales y sociales que hoy sorprenden por su actualidad. Por fin, es importante reflexionar sobre el hecho de que las obras de Antonio Berni parecen anunciar la amplia reforma a la Constitución argentina de 1853, realizada en 1949 durante el gobierno de Juan Domingo Perón. Referida reforma trajo la incorporación de nuevos derechos políticos, extensos derechos sociales, estableció la igualdad del hombre y de la mujer, nacionalizó algunos recursos básicos de la economía, entre otros aspectos, pero en 1957 hubo una nueva convención reformadora, durante la dictadura militar, que convalidó la derogación de la Constitución de 1949 y compiló algunos de los derechos laborales en el nuevo artículo 14 bis $^{23}$.

\section{Conclusión: Ferreyra y Berni - la democracia, el lenguaje y las resonancias del arte}

Nos régimes peuvent être dits démocratiques, mais nous ne sommes pas gouvernés démocratiquement. C'est le grand hiatus qui nourrit le désenchantement et le désarroi contemporains. Précisons. Nos régimes sont considérés comme démocratiques au sens où le pouvoir sort des urnes à l'issue d'une compétition ouverte et où nous vivons dans un État de droit qui reconnaît et protège les libertés individuelles. Démocraties certes largement

\footnotetext{
${ }^{23}$ Informaciones obtenidas en: LÓPEZ ALFONSÍN, Marcelo Alberto. Clases sobre Derecho Constitucional. Modalidad intensiva de cursos para el Doctorado. Departamento de Postgrado. Facultad de Derecho. Universidad de Buenos Aires (UBA), enero de 2016.
} 
inachevées. Les représentés se sentent ainsi souvent abandonnés par leurs représentants statutaires, et le peuple, passé le moment électoral, se trouve bien peu souverain (Pierre Rosanvallon, $L e$ bon gouvernement) ${ }^{24}$.

Lo que claramente nutre las similitudes entre Raúl Gustavo Ferreyra y Antonio Berni es el hecho de que ambos ponen en relieve el pueblo como protagonista de sus obras y de aquello que jurista y artista representan por el lenguaje. En otras palabras, para Ferreyra, "sólo el poder constituyente que emana del pueblo, estrictamente, de los ciudadanos que componen el pueblo, debe crear el Derecho Constitucional, sistema que a su vez organiza al Estado Democrático" (Ferreyra, 2014, p. 15); y para Berni, "La obra se realiza plenamente conviviendo con el drama del hombre en su totalidad política, religiosa ${ }^{25}$ y social, y en el infortunio y sobresalto de cada día ${ }^{26}$. A mí me parece que ambos sostienen una reflexión sobre el concepto de democracia en sus diferentes matices y denuncian, así como Rosanvallon lo hizo, las fisuras y los vacíos de nuestros sistemas democráticos que ponen los ciudadanos a la margen de la sociedad. Y si tenemos democracias inacabadas o incompletas, ¿cómo sería posible pensar en la constitucionalidad de las reformas constitucionales?

Ferreyra (2014) enseña que el Derecho Constitucional sólo puede ser creado por el pueblo y si éste no participa efectivamente de las decisiones constitucionales, hay un vicio de

\footnotetext{
24 Nuestros regímenes pueden ser dichos democráticos, pero no somos gobernados democráticamente. Éste es el gran hiato que nutre el desencanto y el desorden contemporáneos. Explicamos. Nuestros regímenes son considerados como democráticos en el sentido de que el poder sale de las urnas como resultado de una disputa abierta, y de que vivimos en un Estado de derecho que reconoce y protege las libertades individuales. Democracias, sin duda, ampliamente incompletas. Los representados se sienten, así, frecuentemente abandonados por sus representantes estatutarios, y el pueblo, pasado el momento electoral, se encuentra muy poco soberano (Rosanvallon, Pierre. Le bon gouvernement. París: Éditions du Seuil, 2015. p.9. Traducción mía).

25 En este sentido, creo que es interesante también pensar en su antítesis, o sea, como oposición o contrariedad a la posible totalidad religiosa del hombre planteada por Berni.

26 Pensamiento de Antonio Berni citado por: PEPE, Pablo F. Op. Cit.. - $1^{\text {a }}$ ed. - Don Torcuato: Autores de Argentina, 2009.
} 
representatividad que contamina seriamente el orden jurídico y que vuelve inconstitucional todo y cualquier mecanismo de reforma a las constituciones. Advierte el constitucionalista que han sido realizadas muchas investigaciones en el medio académico en búsqueda de las definiciones de democracia. Delante del "exceso de significados atribuibles" al término democracia, estoy de acuerdo con Ferreyra de que hay serias razones para desconfiar de conceptos acabados o unitarios sobre lo que sea efectivamente la democracia. Así, lo que se debe plantear como reflexión jurídica es cómo se da la legitimación democrática y "si democracia indica o se refiere a una peculiar doctrina política, según la cual el poder de autoorganización pertenece al conjunto de los ciudadanos" (Ferreyra, 2014, p. 38).

Tanto Berni como Ferreyra muestran que existen posturas que niegan el Estado democrático. La retratación del pueblo en desocupación o en acto de manifestación por "pan y agua" propuesta por el realismo berniano revela que algo no va bien en las formas de ejercicio del poder o que hay "crisis de representación” en los regímenes dichos democráticos. Ferreyra enseña que los momentos en que el gobierno adopta decisiones en lugar del pueblo son llamados de momentos corrientes. En éstos "no existe ni la movilización ni el debate popular que caracteriza propiamente a la forma más alta de legitimación democrática antes descripta" (Ferreyra, 2014, p. 51). Sin embargo, advierte el constitucionalista que la ausencia de debate popular no necesariamente produce vicio en las decisiones del gobierno durante los momentos corrientes, "siempre que determinadas condiciones institucionales sean satisfechas" (Ferreyra, 2014, p. 52).

Ferreyra destaca con su brillante constitucionalismo realista cuál debe ser el tono del leguaje que corresponde al Derecho Constitucional volcado hacia una "rigurosa concepción de las garantías constitucionales". En este sentido, enseña que "las garantías son diseñadas para acortar las orillas que habitualmente separan lo ordenado por la prescripción enunciada en el texto constitucional y por el sentido que la práctica de las autoridades 
a cargo del gobierno pueda aplicarle incorrectamente" (Ferreyra, 2014, p. 83). Eso nos remite a una idea nuclear:

que "la política debería ser constitucionalmente adecuada", por lo que se descarta de plano la posibilidad de que la constitución pueda ser políticamente adaptada según el paladar o antojo de quienes representen circunstancialmente la voluntad del cuerpo electoral (Ferreyra, 2014. p. 83).

Importante comentar que la Constitución no debe perder su vínculo de identidad entre el tiempo y la realidad a los cuales se dirigen sus prescripciones, aunque referida realidad esté sujeta a los cambios históricos del porvenir. Incluso delante de las cambiantes circunstancias históricas, la Constitución debe mantener su identidad, resguardando su fuerza normativa, y el único modo de hacer eso es por medio de una reforma que tenga como presupuesto el hecho de que el pueblo "es el sujeto que tiene derecho a cambiarla o modificarla cuando en libre y democrática decisión política fundamental considere oportuno y necesario disponerlo" (Ferreyra, 2014, p. 96), de manera que referida reforma pueda respaldar el propio compromiso constitucional que, a su vez, canaliza los preceptos de la democracia. Por lo tanto, si como ilustra el Preámbulo de las constituciones (me refiero tanto a la argentina como a la brasileña) son los representantes del pueblo quienes las ordenaron, las decretaron y las establecieron (tomando con muchas pinzas el término "representantes"), se puede concluir que la reforma constitucional también sólo puede ocurrir mediante una decisión del pueblo, mejor diciendo, una decisión de la voluntad de los ciudadanos que integran el pueblo, pues ésta posee mayor autoridad. Así, "el plan constitucional debe ser decidido por su creador: el cuerpo electoral" (Ferreyra, 2014, p. 96).

En este sentido, tanto Ferreyra, con su lenguaje del derecho, como Berni, con sus resonancias del arte, parecen trazar los presupuestos necesarios para la comprensión de la ingeniería del poder y sus procesos democráticos que se dan por medio de la participación popular, lo que pone en evidencia la noción del 
humanismo retratado en el "nuevo realismo" estético de Antonio Berni. No quedan dudas, en mi opinión, de que tanto Ferreyra como Berni destacan la convicción humanista de que es el hombre la justa medida de todas las cosas -tanto en lo estético como en lo constitucional-, justificación que se entresaca del realismo constitucionalista berniano y del constitucionalismo realista de Ferreyra, al poner como centro de todo y cualquier debate el componente humano latinoamericano con sus diversidades y singularidades pintadas en múltiples rostros, razas, géneros y perfiles que configuran el aspecto idiosincrásico del ser y del tiempo, y que forman las narrativas del pueblo con su necesario protagonismo en las arenas políticas y, consiguientemente, en la creación del Derecho Constitucional.

\section{Referencias}

Barthes, Roland. El susurro del lenguaje - Más allá de la palabra y la escritura. 1. ed. (Título original: Le Bruissement de la langue, traducción: C. Fernández Medrano). Ciudad Autónoma de Buenos Aires: Paidós, 2013.

Charaudeau, Patrick. Langages et discours. Paris : Hachette, 1983.

- Des conditions de la mise en scène du langage. In: DECROSSE, Anne (dir.). L'esprit de société : vers une anthropologie social du sens. Paris: Mardaga, 1993. p. 27-65.

- De la competencia social de comunicación a las competencias discursivas. Revista Lationoamericana de Estudios del Discurso, Caracas, v.1, n. 1, p. 7-22, ago.2001. Disponible en: <http:// www.patrick-charaudeau.com/De-la-competencia-social-de. html > A Accedido el 12 de febrero de 2016.

Contenido sobre Antonio Berni para docentes. Disponible en: $<\mathrm{http}$ ://coleccion.educ.ar/coleccion/CD5/contenidos/docentes/ recursos/2sobre-berni.html> Accedido el 10 de febrero de 2016.

Ferreyra, Raúl Gustavo. Reforma constitucional y control de constitucionalidad. $1^{\mathrm{a}}$ ed. Ciudad Autónoma de Buenos Aires: Ediar, 2014.

- Clases sobre Reforma Constitucional. Modalidad intensiva de cursos para el Doctorado. Departamento de Postgrado. 
Facultad de Derecho. Universidad de Buenos Aires (UBA), enero de 2016.

Frases de Antonio Berni. Disponibles en: <http://www.literato.es/ autor/antonio_berni/> Accedido el 10 de febrero de 2016.

Foucault, Michel. La Arqueología del Saber (Título en original: L' Archéologie du Savoir; traducción de Aurelio Garzón del Camino). Buenos Aires: Siglo XXI Editores Argentina, 2002.

Historias de la Argentina. (Enciclopedia Virtual). Disponible en: <http://www.todo-argentina.net/historia/decadainf/justo/ 1934.html> Accedido el 10 de febrero de 2016.

López Alfonsín, Marcelo Alberto. Clases sobre Derecho Constitucional. Modalidad intensiva de cursos para el Doctorado. Departamento de Postgrado. Facultad de Derecho. Universidad de Buenos Aires (UBA), enero de 2016.

Museo de Arte Latinoamericano de Buenos Aires - Fundación Costantini. Disponible en: <http://www.malba.org.ar $>$ Accedido el 12 de febrero de 2016. Visitado en enero de 2016.

Noticias sobre la Argentina y Antonio Berni. Disponibles en: $<$ http://www.elintransigente.com/argentina > Accedido el 10 de febrero de 2016.

Obras y biografía de Antonio Berni. Disponibles en <http:// www.malba.org.ar/wp-content/uploads/2014/04/Berni. pdf> y también en: <http://cvaa.com.ar/02dossiers/berni/6_ obras_1934_1.php> Accedidos el 10 de febrero de 2016.

Pepe, Pablo F. Un hombre, un pintor, un maestro: Pablo F Pepe. $1^{\mathrm{a}}$ ed. - Don Torcuato: Autores de Argentina, 2009.

Ravetti, Graciela; Arbex, Márcia (org.). Performance, exílio, fronteiras: errâncias territoriais e textuais. Belo Horizonte: Departamento de Letras Românicas, Faculdade de Letras / UFMG: Poslit, 2002.

Rosanvallon, Pierre. Le bon gouvernement. París : Éditions du Seuil, 2015.

Russell, Bertrand. Nuestro conocimiento del mundo externo. Buenos Aires: Losada, 1946.

Valadés, Diego. La lengua del Derecho y el derecho de la lengua, discurso de ingreso a la Academia Mexicana de la Lengua. 25 de agosto de 2005, Universidad Autónoma de México y Academia Mexicana de la Lengua. México, 2005. 